\title{
Dendrite-free Li deposition using trace-amounts of water as an electrolyte additive
}

Jiangfeng Qian ${ }^{\mathrm{a}}, \mathrm{Wu} \mathrm{Xu^{ \textrm {a } } * \text { , Priyanka Bhattacharya }}{ }^{\mathrm{a}}$, Mark Engelhard ${ }^{\mathrm{b}}$, Wesley A. Henderson ${ }^{\mathrm{a}}$, Yaohui Zhang ${ }^{\mathrm{a}, \mathrm{c}}$, Ji-Guang Zhang ${ }^{\mathrm{a}, *}$

${ }^{a}$ Joint Center for Energy Storage Research, Energy and Environment Directorate, Pacific Northwest National Laboratory, Richland, Washington 99354, USA

bJoint Center for Energy Storage Research, Environmental and Molecular Sciences Laboratory, Pacific Northwest National Laboratory, Richland, Washington 99354, USA

${ }^{c}$ Department of Physics, Harbin Institute of Technology, Harbin, Heilongjiang 150001, China

*Corresponding authors: Tel.: 509-372-6515, E-mail address: jiguang.zhang@pnnl.gov (J.-G. Zhang); Tel.: 509-375-6934, E-mail address: wu.xu@ pnnl.gov (W. Xu).

\begin{abstract}
Residual water $\left(\mathrm{H}_{2} \mathrm{O}\right)$ presents in nonaqueous electrolytes has been widely regarded as a detrimental factor for lithium (Li) batteries. This is because $\mathrm{H}_{2} \mathrm{O}$ is highly reactive with the commonly used $\mathrm{LiPF}_{6}$ salt leading to the formation of HF which subsequently corrodes battery materials. In this work, we demonstrate that a controlled trace-amount of $\mathrm{H}_{2} \mathrm{O}$ (25-50 ppm) can be an effective electrolyte additive for achieving dendrite-free Li metal deposition in $\mathrm{LiPF}_{6}$ based electrolytes, while avoid detrimental effects. Detailed analyses revealed that the trace amount of $\mathrm{HF}$ derived from the decomposition reaction of $\mathrm{LiPF}_{6}$ with $\mathrm{H}_{2} \mathrm{O}$ is electrochemically reduced during the initial $\mathrm{Li}$ deposition process to form a uniform and dense LiF-rich solid electrolyte interphase (SEI) layer on the surface of the substrate. This LiF-rich SEI layer leads to a uniform distribution of the electric field on the substrate surface thereby enabling uniform and dendrite-free $\mathrm{Li}$ deposition. Meanwhile, the detrimental effect of $\mathrm{HF}$ on the other cell components is diminished due to the consumption of the $\mathrm{HF}$ in the $\mathrm{LiF}$ formation process. Microscopic analysis reveals that the as-deposited, dendrite-free Li films exhibit a self-aligned and highly-compact Li nanorod structure which is consistent with a vivid blue color due to structural coloration. These findings clearly demonstrate a novel approach to control the nucleation and grow processes of Li metal films using a well-controlled, trace-amount of $\mathrm{H}_{2} \mathrm{O}$, as well as illuminate the effect of $\mathrm{H}_{2} \mathrm{O}$ on other electrodeposition processes.
\end{abstract}

Key words: Li deposition; dendrite-free; water additive; LiF; SEI layer 


\section{Introduction}

Lithium ( $\mathrm{Li}$ ) metal has been widely considered to be one of the most attractive high energy anode materials for the next-generation rechargeable batteries-such as those based upon $\mathrm{Li}-\mathrm{S}$ and $\mathrm{Li}-\mathrm{O}_{2}$ chemistries, as well as other $\mathrm{Li}$ metal batteries with intercalation compounds as the cathode-because of Li metal's ultrahigh theoretical capacity (3860 $\mathrm{mAh} \mathrm{g}^{-1}$ ), very low negative reduction potential ( $-3.040 \mathrm{~V}$ vs. SHE), and low density $\left(0.534 \mathrm{~g} \mathrm{~cm}^{-3}\right)$ [1-3]. However, dendrite growth during repeated Li deposition/stripping cycles and a low Coulombic efficiency for these processes remain as two major problems which preclude the widespread application of $\mathrm{Li}$ metal anodes in rechargeable batteries. In particular, $\mathrm{Li}$ dendrite growth or mossy $\mathrm{Li}$ generation can accelerate the capacity fade of the battery due to the formation of electrically isolated $\mathrm{Li}$ (i.e., "dead" $\mathrm{Li}$ unavailable for the battery reaction). Of even greater concern, however, is the potential for the Li dendrites to penetrate through the separator, causing internal short circuiting followed by thermal runaway of the battery, which is unacceptable for commercial applications.

Over the past 40 years, tremendous effort has been devoted to observing [4, 5], analyzing $[6,7]$ and modeling [8-10] the formation/growth of $\mathrm{Li}$ dendrites. The concept of a solid electrolyte interphase (SEI) proposed by Peled [11] in 1979 has been extensively investigated as part of these studies. Li metal is known to be thermodynamically unstable with organic electrolyte constituents. Once $\mathrm{Li}$ metal contacts the electrolyte, it rapidly reacts with the solvent(s) and/or salt anions in the electrolyte to form an electrically insulating, but ionically conductive SEI layer that physically prevents the direct contact between the Li metal and electrolyte [12]. This SEI layer has been revealed to mainly consist of $\mathrm{ROCO}_{2} \mathrm{Li}, \mathrm{ROLi}, \mathrm{Li}_{2} \mathrm{CO}_{3}$, and/or LiF, depending upon the electrolyte composition [13]. However, it has been reported by Aurbach [14] that these SEI layer components are usually not robust enough to accommodate the rapid changes in the morphology of the Li layer underneath and thus cracks occur as a result of the breakdown and reparation of the surface films during the Li deposition/stripping processes. ENREF $16 \mathrm{Li}$ metal protrusions can therefore grow out from these cracks and $\mathrm{Li}^{+}$ cations may preferentially deposit on them to form Li dendrites. A recent work by Sacci et al. [15] using in situ electrochemical transmission electron microscopy (TEM) revealed that the random ordering of the SEI plays a role in the subsequent Li dendrite formation. Therefore, the stability and uniformity of the SEI layer is one of the most critical factors that determine the Li deposition morphology. A more uniform SEI film leads to more homogeneous ion conduction across the deposition area and decreases protuberant tip formation. Thus, a stronger SEI film may effectively suppress Li dendrite growth.

To improve the interfacial stability of the Li electrode, a variety of strategies have been investigated, including the use of different electrolyte solvents, salts, and additives [2, 16, 17]. For instance, hydrofluoric acid (HF) was proposed by Kanamura et al. as an additive to modify the SEI layer [18, 19]. A small amount of HF was added to a liquid electrolyte and the HF reacted, via an acid-base reaction, with the native $\mathrm{Li}$ surface layers, which were mainly composed of $\mathrm{Li}_{2} \mathrm{O}, \mathrm{LiOH}$, and $\mathrm{Li}_{2} \mathrm{CO}_{3}$, to produce a $\mathrm{LiF}-\mathrm{Li}_{2} \mathrm{O}$ bilayer. This SEI layer was reported to be dense and uniform and therefore induced a uniform current distribution during $\mathrm{Li}$ deposition and dissolution. Recently, Togasaki et al reported that trace amount of $\mathrm{H}_{2} \mathrm{O}$ accompanied with $\mathrm{CO}_{2}$ can significantly improve the cycling performance of Li metal anode [20]. The beneficial effect of $\mathrm{LiF}$ on Li electrodeposition was also reported by Archer and coworkers [21], ENREF 19 who found that simple liquid electrolytes with the lithium bis(trifluoromethanesulfonyl)imide $\left(\mathrm{LiN}\left(\mathrm{SO}_{2} \mathrm{CF}_{3}\right)_{2}\right.$ or LiTFSI) salt and propylene carbonate (PC) 
solvent (i.e., 1.0 M LiTFSI-PC), when reinforced with $30 \mathrm{~mol} \% \mathrm{LiF}$ salt blends, could lead to stable long-term cycling of a $\mathrm{Li}$ metal electrode at room temperature. For such approaches, however, it is difficult to handle the HF addition in commercial electrolyte production processes since HF is highly toxic and corrosive, while LiF salt has extremely low solubility in common organic solvents. Therefore, the addition of $30 \mathrm{~mol} \% \mathrm{LiF}$ in the electrolyte actually results in a suspension of $\mathrm{LiF}$ which decreases the ionic conductivity of the electrolytes by about one order of magnitude (to only $1.3 \mathrm{mS} \mathrm{cm}^{-1}$ ) which is not favorable for practical applications.

Recently, we have found that $\mathrm{Cs}^{+}$cations as an additive promote the formation of an underlying SEI enriched in $\mathrm{LiF}$ which formed at about $2.05 \mathrm{~V}$ during the initial $\mathrm{Li}$ deposition process and lead to dendrite-free $\mathrm{Li}$ deposition [17]. Herein, we further demonstrate that by intentionally adding trace amounts of water $\left(\mathrm{H}_{2} \mathrm{O}\right)$ into a lithium hexafluorophosphate $\left(\mathrm{LiPF}_{6}\right)$ based electrolyte, $\mathrm{HF}$ can be generated by the hydrolysis reaction of the $\mathrm{PF}_{6}{ }^{-}$anions. During the initial $\mathrm{Li}$ deposition process, the $\mathrm{H}_{2} \mathrm{O}$-induced $\mathrm{HF}$ can then be in situ reduced electrochemically to form a thin and dense LiF-rich SEI layer on a copper $(\mathrm{Cu})$ substrate at a potential above that of the $\mathrm{Li}$ deposition. This thin SEI layer is uniform and dense, and allows $\mathrm{Li}^{+}$cations transport while minimizing the corrosion of the freshly deposited Li metal by the electrolyte, thus resulting in a dendrite-free $\mathrm{Li}$ film. To explore this in greater depth, the morphologies of $\mathrm{Li}$ films deposited using various conditions and the mechanism of the dendrite-free Li growth have been investigated by both optical and SEM analyses.

\section{Materials and methods}

$\mathrm{LiPF}_{6}, \mathrm{PC}$, dimethyl carbonate (DMC) and fluoroethylene carbonate (FEC) were purchased from BASF Corporation in battery-grade and used without further purification. The $\mathrm{H}_{2} \mathrm{O}$ content of the electrolytes was determined by Karl Fischer titration, while the HF level was estimated using an acid-base titration technique, as described in the literature [22]. Plastic Nalgene flasks instead of glassware were used when handling the electrolyte samples because of the corrosive nature of $\mathrm{HF}$ towards glass. The commercial PC solvent contains about $13 \mathrm{ppm}$ $\mathrm{H}_{2} \mathrm{O}$ as determined by Karl Fisher titration. An additional $\mathrm{H}_{2} \mathrm{O}(10-200 \mathrm{ppm})$ was introduced into the prepared 1.0 $\mathrm{M} \mathrm{LiPF}_{6}-\mathrm{PC}$ electrolyte using a micropipette. The extent of hydrolysis was monitored by measuring the $\mathrm{H}_{2} \mathrm{O}$ content and $\mathrm{HF}$ level in the electrolytes at predetermined time intervals.

$\mathrm{Li}$ metal was deposited on $\mathrm{Cu}$ foil substrates $(10 \mathrm{~mm} \times 10 \mathrm{~mm})$ in $1.0 \mathrm{M} \mathrm{LiPF}_{6}-\mathrm{PC}$ electrolyte solutions with or without $\mathrm{H}_{2} \mathrm{O}$ as an additive at the selected current densities inside an Ar-filled glovebox using a Solartron electrochemical interface (SI 1287). After Li deposition, the electrode was washed with DMC to remove the residual electrolyte and then dried under vacuum in the antechamber of the glovebox prior to characterization and analyses. SEM images of the deposited Li electrodes for both the surfaces and cross-sections were obtained with a FEI Quanta FESEM at an accelerating voltage of $5 \mathrm{kV}$. The surface element components were determined by means of an energy dispersive X-ray fluorescence spectrometer (EDX). X-ray photoelectron spectroscopy (XPS) measurements of the compositions of the SEI layers were performed with a Physical Electronics Quantera scanning X-ray microprobe with a focused monochromatic Al K $\alpha$ X-ray $(1486.7 \mathrm{eV})$ source for excitation and a spherical section analyzer. To avoid electrode contamination or side reactions with atmospheric moisture and oxygen, the samples were transferred from the glove box to the SEM and XPS in sealed vessels which were filled with argon gas. 


\section{Results and Discussion}

\section{$\mathrm{LiPF}_{6}$ decomposition $\mathrm{HF}$ formation in the presence of $\mathrm{H}_{2} \mathrm{O}$}

Residual $\mathrm{H}_{2} \mathrm{O}$ in nonaqueous electrolytes is often regarded as a detrimental factor for $\mathrm{Li}$ metal and Li-ion batteries due to its ease of reduction at the anode to generate $\mathrm{H}_{2}$ and oxidization at the cathode to release $\mathrm{O}_{2}$, as well as its high reactivity with the commonly used $\mathrm{LiPF}_{6}$ salt to produce $\mathrm{HF}$ in the electrolyte which may then corrode the battery materials present [23]. However, it is well known that the electrolytes used in Li-ion batteries unavoidably contain trace-amounts of $\mathrm{H}_{2} \mathrm{O}$. The best commercially available Li battery-grade electrolyte solutions usually contain $\sim 10 \mathrm{ppm} \mathrm{H}_{2} \mathrm{O}$. Many cathode materials, such as $\mathrm{LiMn}_{2} \mathrm{O}_{4}$, can also be highly hygroscopic and, thus, also introduce considerable $\mathrm{H}_{2} \mathrm{O}$ contamination into $\mathrm{Li}$ ion batteries [24]. The hydrolysis reaction of $\mathrm{LiPF}_{6}$ in the presence of $\mathrm{H}_{2} \mathrm{O}$ happens as follows [25] :

$$
\mathrm{LiPF}_{6}+\mathrm{H}_{2} \mathrm{O} \rightarrow \mathrm{POF}_{3}+\mathrm{LiF}+2 \mathrm{HF}
$$

Accordingly, one mole of $\mathrm{H}_{2} \mathrm{O}$ will generate approximately two mole of $\mathrm{HF}$. This $\mathrm{H}_{2} \mathrm{O}-$ induced HF is typically thought to result in poor cell performance. However, Dahn and coworkers [26] found that the addition of 100-1000 ppm of $\mathrm{H}_{2} \mathrm{O}$ into electrolytes had only a minimal effect on the performance of Li-ion cells. In some cases, cells with $\mathrm{H}_{2} \mathrm{O}$-added electrolytes even had superior performance, as compared to those without $\mathrm{H}_{2} \mathrm{O}$. Gasteiger et al. [27] also found that $\mathrm{H}_{2} \mathrm{O}$ acts as promoter in $\mathrm{O}_{2}$ reduction electrochemistry in non-aqueous $\mathrm{Li}-\mathrm{O}_{2}$ batteries. However, the details of the reaction route of $\mathrm{H}_{2} \mathrm{O}$ in battery systems still need to be clarified.

In this work, in order to quantitatively investigate the hydrolysis reaction of a $\mathrm{LiPF}_{6}$ based electrolyte towards $\mathrm{H}_{2} \mathrm{O}$, select amounts of $\mathrm{H}_{2} \mathrm{O}$ were added to a $1.0 \mathrm{M} \mathrm{LiPF}_{6}-\mathrm{PC}$ control electrolyte and the concentrations of $\mathrm{H}_{2} \mathrm{O}$ and $\mathrm{HF}$ were monitored as a function of storage time after the $\mathrm{H}_{2} \mathrm{O}$ addition [22]. Fig. 1a shows the evolution of $\mathrm{H}_{2} \mathrm{O}$ and $\mathrm{HF}$ with time for the electrolyte with $50 \mathrm{ppm}_{2} \mathrm{O}$ as an additive. It should be noted that the commercial PC solvent already contained about 13 ppm $\mathrm{H}_{2} \mathrm{O}$, which made the initial $\mathrm{H}_{2} \mathrm{O}$ content to be $\sim 63 \mathrm{ppm}$ when another $50 \mathrm{ppm} \mathrm{H}_{2} \mathrm{O}$ was added. The $\mathrm{LiPF}_{6}$ salt itself may also contain small amounts of HF from the reaction with residual $\mathrm{H}_{2} \mathrm{O}$ prior to its incorporation into the electrolyte, but this amount of $\mathrm{HF}$ will be the same for all of the prepared electrolytes. As shown in Fig. 1a, the added $\mathrm{H}_{2} \mathrm{O}$ was quickly consumed (within $\sim 48 \mathrm{~h}$ ) by the reaction with $\mathrm{LiPF}_{6}$, generating a large amount of acidic species (which are represented by $\mathrm{HF}$ in this work) in the electrolyte. After $48 \mathrm{~h}$, the HF amount stabilized at $\sim 100 \mathrm{ppm}$, while the $\mathrm{H}_{2} \mathrm{O}$ amount dropped to $<10 \mathrm{ppm}$. Therefore, all of the electrolytes with the $\mathrm{H}_{2} \mathrm{O}$ additive were stored for $48 \mathrm{~h}$ prior to the Li deposition work conducted in this investigation. Fig. $1 \mathrm{~b}$ shows that the amount of $\mathrm{HF}$ measured after $48 \mathrm{~h}$ increases nearly linearly with the amount of $\mathrm{H}_{2} \mathrm{O}$ (from 10-250 ppm) added in the control electrolyte and is about twice as much as that of the added $\mathrm{H}_{2} \mathrm{O}$, consistent with the reaction shown in Eqn. (1). 

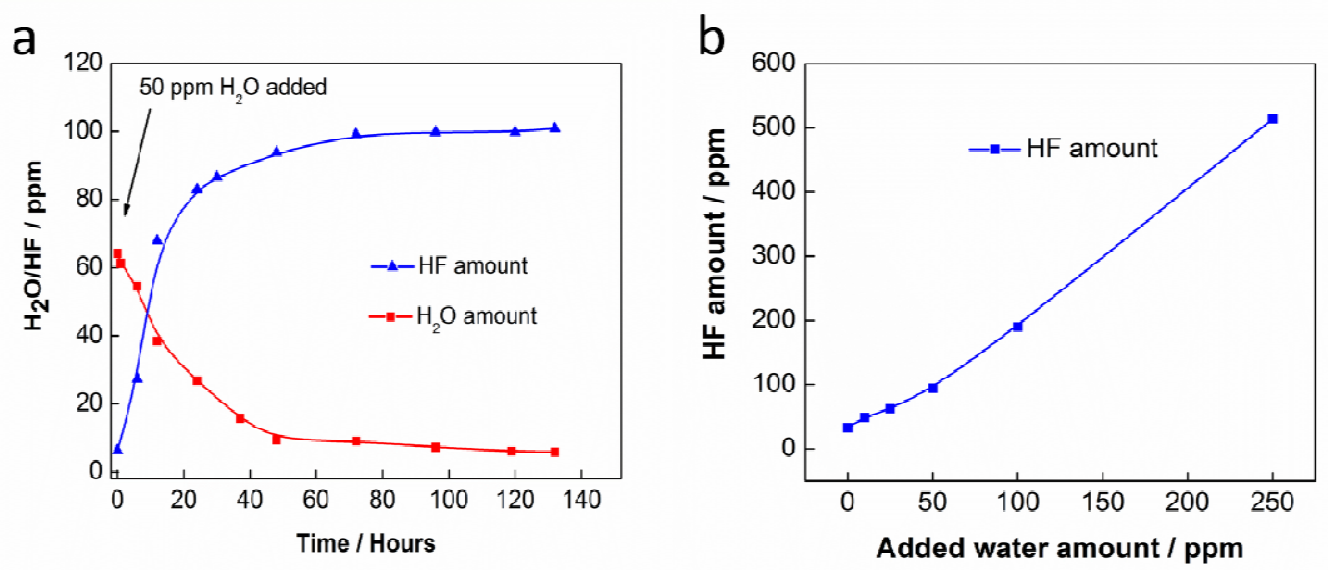

Fig. 1. (a) Evolution of $\mathrm{H}_{2} \mathrm{O}$ and $\mathrm{HF}$ with storage time for the $1.0 \mathrm{M} \mathrm{LiPF}_{6}-\mathrm{PC}$ electrolyte after the addition of 50 ppm $\mathrm{H}_{2} \mathrm{O}$. (b) Variation of the $\mathrm{HF}$ content with added $\mathrm{H}_{2} \mathrm{O}$ in the electrolyte, where the $\mathrm{HF}$ content was measured at $48 \mathrm{~h}$ after the addition of $\mathrm{H}_{2} \mathrm{O}$.

\section{Li deposition behavior in electrolytes without/with added $\mathrm{H}_{2} \mathrm{O}$}

The electrolytes with different amounts of the $\mathrm{H}_{2} \mathrm{O}$ additive (from 10-250 ppm) were used for the Li deposition tests. As shown in Fig. S1, a distinct Li deposition morphology change was observed even when only $10 \mathrm{ppm}$ of $\mathrm{H}_{2} \mathrm{O}$ (in addition to $\sim 13 \mathrm{ppm}$ of $\mathrm{H}_{2} \mathrm{O}$ in the control electrolyte) was introduced into the electrolyte, while the addition of $50 \mathrm{ppm} \mathrm{of} \mathrm{H}_{2} \mathrm{O}$ leads to the smoothest Li deposition morphology. However, a higher concentration of added $\mathrm{H}_{2} \mathrm{O}(>100$ ppm) results in excessive corrosion of the Li metal due to the high amount of HF present. These results indicate that $\sim 50 \mathrm{ppm}$ of $\mathrm{H}_{2} \mathrm{O}$ is an optimized amount of added $\mathrm{H}_{2} \mathrm{O}$ for obtaining the best $\mathrm{Li}$ deposition morphology. Therefore, the details of the $\mathrm{Li}$ deposition process in an electrolyte consisting of $1.0 \mathrm{M} \mathrm{LiPF} 6-\mathrm{PC}$ with an additional $50 \mathrm{ppm}$ of $\mathrm{H}_{2} \mathrm{O}$ were systematically investigated in this work, unless otherwise indicated.

Fig. 2 shows the optical morphologies of the deposited $\mathrm{Li}$ films on the $\mathrm{Cu}$ substrates from the

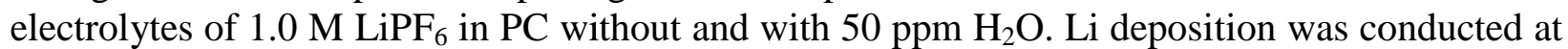
a current density of $0.1 \mathrm{~mA} \mathrm{~cm}^{-2}$ for $15 \mathrm{~h}$. The $\mathrm{Li}$ deposited on the $\mathrm{Cu}$ substrate in the control electrolyte (1.0 $\mathrm{M} \mathrm{LiPF}_{6}-\mathrm{PC}$ ) has a typical dendritic form and gray color (Fig. 2a). In contrast, the $\mathrm{Li}$ deposited in the electrolyte with the $50 \mathrm{ppm}$ of $\mathrm{H}_{2} \mathrm{O}$ shows a significant improvement in the Li film surface quality with the elimination of dendrite formation (Fig. 2b). The Li film is mirror-like smooth and dense, resulting in a brilliant blue color. Actually, this vibrant blue color resembles very much the color of the Morpho butterfly [28], which is known to reflect blue light by arrays of precise and repeated microstructures on its wing, rather than from the presence of pigments. This is clear evidence that the blue color of the deposited Li film originates from its ordered microstructure which interacts with light to produce the blue color. It is interesting to note that the addition of $\mathrm{H}_{2} \mathrm{O}$ itself does not improve the $\mathrm{Li}$ deposition morphology. If the $\mathrm{Li}$ deposition is conducted directly after the $\mathrm{H}_{2} \mathrm{O}$ is added, then a dendritic $\mathrm{Li}$ deposit is still formed, similar to those shown in Fig. S1. In addition, if the $\mathrm{LiPF}_{6}$ salt was substituted with lithium bis(trifluoromethanesulfonyl)imide ( $\mathrm{LiN}\left(\mathrm{SO}_{2} \mathrm{CF}_{3}\right)_{2}$ or LiTFSI), which is known to be stable against $\mathrm{H}_{2} \mathrm{O}$ [29], the $\mathrm{Li}$ deposit is also dendritic. These results indicate that the hydrolysis product of $\mathrm{LiPF}_{6}$ (i.e., the formation of $\mathrm{HF}$ ) is critical for the smooth deposition of Li metal. 

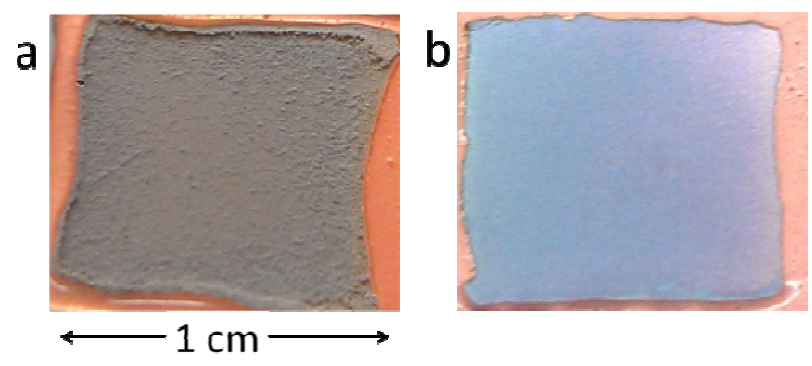

Fig. 2. Optical images of the Li films deposited on $\mathrm{Cu}$ substrates obtained from the $1.0 \mathrm{M} \mathrm{LiPF}_{6^{-}}$ $\mathrm{PC}$ electrolytes (a) without and (b) with the $50 \mathrm{ppm} \mathrm{H}_{2} \mathrm{O}$ additive. The reddish-brown color at the edges is the $\mathrm{Cu}$ substrate.

To further investigate the mechanism related to the smooth Li deposition in the electrolyte with trace amount of $\mathrm{H}_{2} \mathrm{O}$ additive, the voltage profiles during the $\mathrm{Li}$ deposition process were carefully analyzed. Fig. 3a shows the voltage-time profiles of the Li deposition process in these two electrolytes. The deposition voltage profiles can be divided into two parts: one is the region above $0 \mathrm{~V}$ which corresponds to the electrochemical decomposition of the solvent, salt, additives and/or impurities to form the SEI films, while the second is the region below $0 \mathrm{~V}$ which is ascribed to the Li metal plating process. In the control electrolyte (the black line in Fig. 3a), the voltage curve drops sharply from the open circuit voltage (OCV) to about $1.0 \mathrm{~V} \mathrm{vs}$. $\mathrm{Li}^{2} / \mathrm{Li}^{+}$, followed by a sloped curve between $1.0 \mathrm{~V}$ and $0 \mathrm{~V}$, which can be mainly attributed to the reduction of the PC solvent on the substrate surface to form the SEI film. An XPS elemental analysis of this SEI layer (Fig. 3c and 3d) formed before the Li deposition, i.e., the experiment was terminated at $>0 \mathrm{~V}$-see Fig. 3a, shows a large amount of $\mathrm{C}(41.2 \%)$ and $\mathrm{O}(16.6 \%)$, characteristic of lithium alkyl carbonate $\mathrm{ROCO}_{2} \mathrm{Li}$ species, i.e., $\mathrm{C}_{3} \mathrm{H}_{6}\left(\mathrm{OCO}_{2} \mathrm{Li}\right)_{2}$, resulting from

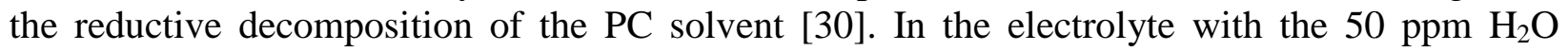
additive (the red line in Fig. 3a), however, a high voltage plateau occurred at $\sim 2.6 \mathrm{~V}$, which can be ascribed to the electrochemical reduction of the $\mathrm{HF}$ to form a $\mathrm{LiF}$ layer on the $\mathrm{Cu}$ substrate at this potential (Fig. S2). Additionally, a small adjacent plateau occurred at $\sim 2.2 \mathrm{~V}$, which is possibly due to the further reduction of $\mathrm{POF}_{3}$ species to form $\mathrm{LiF}$ or $\mathrm{LiPOF}_{\mathrm{x}}$. Between $1.0 \mathrm{~V}$ and $0 \mathrm{~V}$, the PC reduction is obviously suppressed with only a limited steep slope noted during this potential range, as compared with the CV for the standard electrolyte (Fig. S2). The CV (Fig. 3b) of the $\mathrm{H}_{2} \mathrm{O}$-added electrolyte also shows two adjacent large peaks at $2.6 \mathrm{~V}$ and $2.2 \mathrm{~V}$, while the current response below $1.0 \mathrm{~V}$ is much smaller than that of the control electrolyte, consistent with the voltage curves shown in Fig. 3a. An XPS elemental analysis of this SEI layer (Fig. 3c and 3d) formed before the Li deposition also indicates that the $\mathrm{F}$ element $(49.3 \%)$ is a dominant SEI component, with the $\mathrm{C}$ and $\mathrm{O}$ decreased to $11.4 \%$ and $7.3 \%$, respectively. This is direct evidence that the substrate was covered by a thin SEI layer mainly consisting of $\mathrm{LiF}$ rather than $\mathrm{ROCO}_{2} \mathrm{Li}$.

In the control electrolyte, $\mathrm{PC}$ can be decomposed to form lithium alkyl carbonate_ENREF 26 [30]:

$$
2 \mathrm{C}_{4} \mathrm{H}_{6} \mathrm{O}_{3}+2 \mathrm{Li}^{+}+2 \mathrm{e}^{-} \rightarrow \mathrm{C}_{3} \mathrm{H}_{6}\left(\mathrm{OCO}_{2} \mathrm{Li}\right)_{2}+\mathrm{C}_{3} \mathrm{H}_{6}
$$

In the $\mathrm{H}_{2} \mathrm{O}$-added electrolyte, $\mathrm{LiF}$ is formed via the electrochemical reduction of $\mathrm{HF}$ :

$$
2 \mathrm{HF}+2 \mathrm{Li}^{+}+2 \mathrm{e}^{-} \rightarrow 2 \mathrm{LiF}+\mathrm{H}_{2}
$$


a

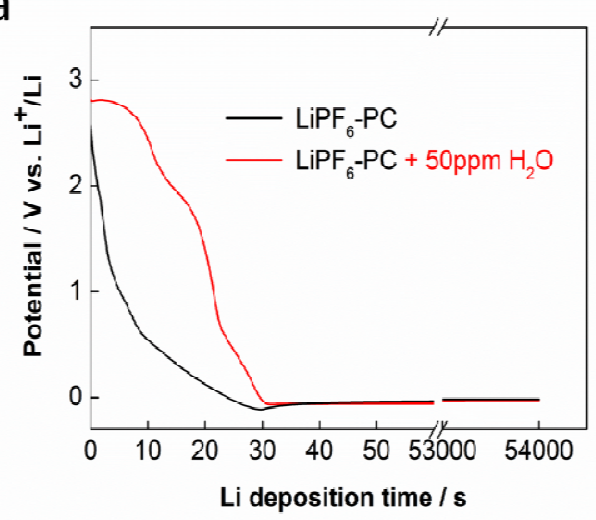

C

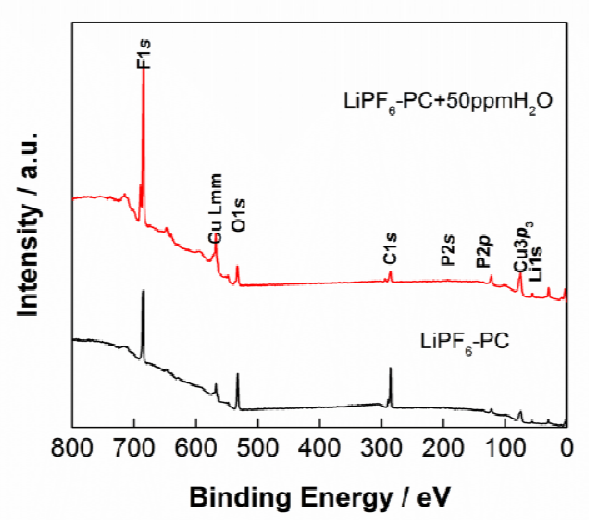

b
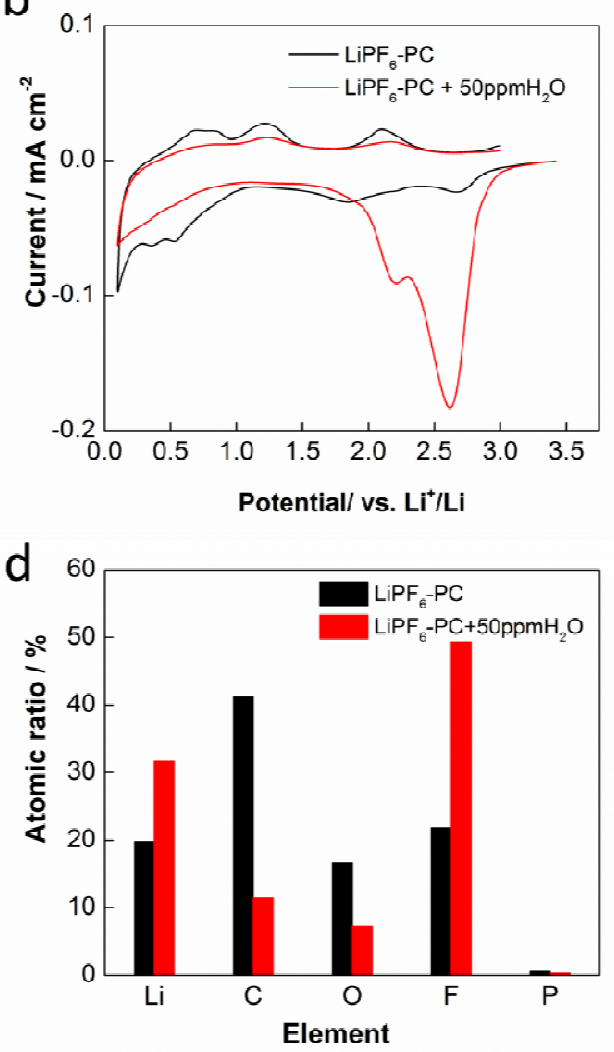

Fig. 3. (a) The voltage-time profiles of the Li deposition process in $1.0 \mathrm{M} \mathrm{LiPF}_{6}-\mathrm{PC}$ electrolytes without and with $50 \mathrm{ppm} \mathrm{H}_{2} \mathrm{O}$ additive for $15 \mathrm{~h}$ at a current density of $0.1 \mathrm{~mA} \mathrm{~cm}^{-2}$. (b) CVs of the two electrolytes at the scan rate of $5 \mathrm{mV} \mathrm{s}^{-1}$. (c) Wide scan XPS spectra for the pre-formed SEI layer in the $1.0 \mathrm{M} \mathrm{LiPF}_{6}-\mathrm{PC}$ electrolytes without and with $\mathrm{H}_{2} \mathrm{O}$. (d) Atomic ratio of elements in the pre-formed SEI layer obtained from the XPS data.

The chemical composition and properties of the pre-formed SEI layers are critical to the subsequent $\mathrm{Li}$ deposition behavior, since the $\mathrm{Li}^{+}$cations needs to be transported through this layer to reach the substrate to be reduced to Li metal underneath the SEI layer. Therefore, the uniformity and mechanical stability of the pre-formed SEI layer strongly affect the morphology of the deposited Li metal films. Several papers have reported studies about the structure-property relationships for individual SEI components [31, 32]. In general, the SEI films dominated by organic components such as lithium alkyl carbonates $\left(\mathrm{ROCO}_{2} \mathrm{Li}\right)$ are found to be porous and fragile with a lower shear modulus of $<1 \mathrm{GPa}$ [32]. In contrast, the SEI films dominated by inorganic crystalline components such as $\mathrm{Li}_{2} \mathrm{CO}_{3}$ [33], $\mathrm{Li}_{2} \mathrm{O}$ [34], and $\mathrm{LiF}$ [35] are much stronger in mechanical strength. Among the various inorganic components, $\mathrm{LiF}$ has the highest shear modulus of $55.1 \mathrm{GPa}\left(45.6 \mathrm{GPa}\right.$ for $\mathrm{Li}_{2} \mathrm{O}$ and $28.9 \mathrm{GPa}$ for $\mathrm{Li}_{2} \mathrm{CO}_{3}$ ). Also, a recent joint density functional theoretical (JDFT) calculation [36] indicated that $\mathrm{LiF}$ facilitates $\mathrm{Li}^{+}$diffusion by more than two orders of magnitude at the Li/electrolyte interface, which may lead to a large improvement in the stability of the Li deposition and dendrite suppression in liquid electrolytes. Thus, a LiF-rich SEI layer favors the formation of dendrite-free Li deposition. 


\section{Nanostructure and composition of $\mathrm{Li}$ Film deposited in an electrolyte with $\mathrm{H}_{2} \mathrm{O}$ additive}

To verify the effect of an in situ formed LiF-rich SEI layer on the Li deposition behavior, we investigated the morphology of the Li films by both optical and scanning electron (SEM) microscopy. The in situ optical microscopic movies were recorded during the electrodeposition of Li films on a $\mathrm{Cu}$ substrate (a $200 \mu \mathrm{m}$ thick copper wire) surface in the electrolytes of $1.0 \mathrm{M}$ $\mathrm{LiPF}_{6}-\mathrm{PC}$ without and with $50 \mathrm{ppm} \mathrm{H}_{2} \mathrm{O}$, as shown in Movies $\mathrm{S} 1$. The movies indicate that the $\mathrm{Li}$ deposited in the control electrolyte $\left(1.0 \mathrm{M} \mathrm{LiPF}_{6}-\mathrm{PC}\right)$ is porous and grows into a large cluster, while for the electrolyte with the $50 \mathrm{ppm}_{2} \mathrm{O}$ additive the deposited $\mathrm{Li}$ is instead thin and dense.

Figs. $4 \mathrm{a}$ and $4 \mathrm{~b}$ show SEM images of the surface and cross-sectional morphologies of a deposited Li film using the control electrolyte (1.0 $\left.\mathrm{M} \mathrm{LiPF}_{6}-\mathrm{PC}\right)$. As expected, the Li film has a typical dendritic microstructure in both the surface and cross-sectional views. The EDX spectrum of this $\mathrm{Li}$ film shows that the surface is dominated by $\mathrm{O}$ and $\mathrm{C}$ elements (from the reduction of the PC solvent, see Fig. 4g). After the addition of $50 \mathrm{ppm}$ of $\mathrm{H}_{2} \mathrm{O}$ to the control electrolyte, a distinctive morphology improvement of the deposited Li film is obtained, as shown in Figs. 4c and $4 \mathrm{~d}$. Dendrite-free Li films were obtained and the as-deposited Li layers are smooth and dense. The thickness of the Li layer measured from Fig. $4 \mathrm{~d}$ is about $9 \mu \mathrm{m}$ which is close to the theoretical value of $8 \mu \mathrm{m}$ calculated (based on a capacity of $1.5 \mathrm{mAh} \mathrm{cm}$ used for the $\mathrm{Li}$ deposition) if the film has no porosity [37]. This result indicates that the Li layer deposited with the $50 \mathrm{ppm} \mathrm{H}_{2} \mathrm{O}$ additive is highly compact and dense. The EDX spectrum shown in Fig. 4h reveals that the element $\mathrm{F}$ dominates the surface layer, indicating that the Li surface is coved by a thin layer of a LiF-based SEI. The EDX linescan elemental profile of the cross section of the Li metal deposited on $\mathrm{Cu}$ substrate (see Fig. S3 in the Supporting Information) shows that the F element was mainly on the near surface of deposited Li layer, but was not detected at the bottom, indicating that the LiF-rich SEI layer was on the top, rather than on the bottom of Li deposits. Figs. $4 \mathrm{e}$ and $4 \mathrm{f}$ show the high resolution images of the surface and the cross-sectional morphologies, respectively. It is interesting to find that the electrochemically deposited $\mathrm{Li}$ film in the electrolyte containing the $\mathrm{H}_{2} \mathrm{O}$ additive is actually composed of well-aligned, highlycompacted nanorods. The diameter of most of the Li nanorods is about $\sim 260 \mathrm{~nm}$. The $\mathrm{Li}$ nanorods grow perpendicularly to the $\mathrm{Cu}$ surface with an even length during the electrodeposition at $0.1 \mathrm{~mA} \mathrm{~cm}^{-2}$ for $15 \mathrm{~h}$. Consistent with the optical image shown in Fig. $2 \mathrm{~b}$, these arrays of uniform structures of $260 \mathrm{~nm}$ nanorods are thought to be the main reason for the film's interaction with light to produce brilliant blue color (i.e., structural coloration). For instance, Sato et al. [28] had investigated the relationship of different periodic structure and the wavelength of light they reflect. An inverse opal film with a center-to-center distance of $275 \mathrm{~nm}$ displays a uniform blue color which extends over the entire film. This characteristic microscopically-ordered structure of $275 \mathrm{~nm}$ is quite close to our result, further confirming that the blue color shown in Fig. $2 \mathrm{~b}$ is attributable to structural coloration. 

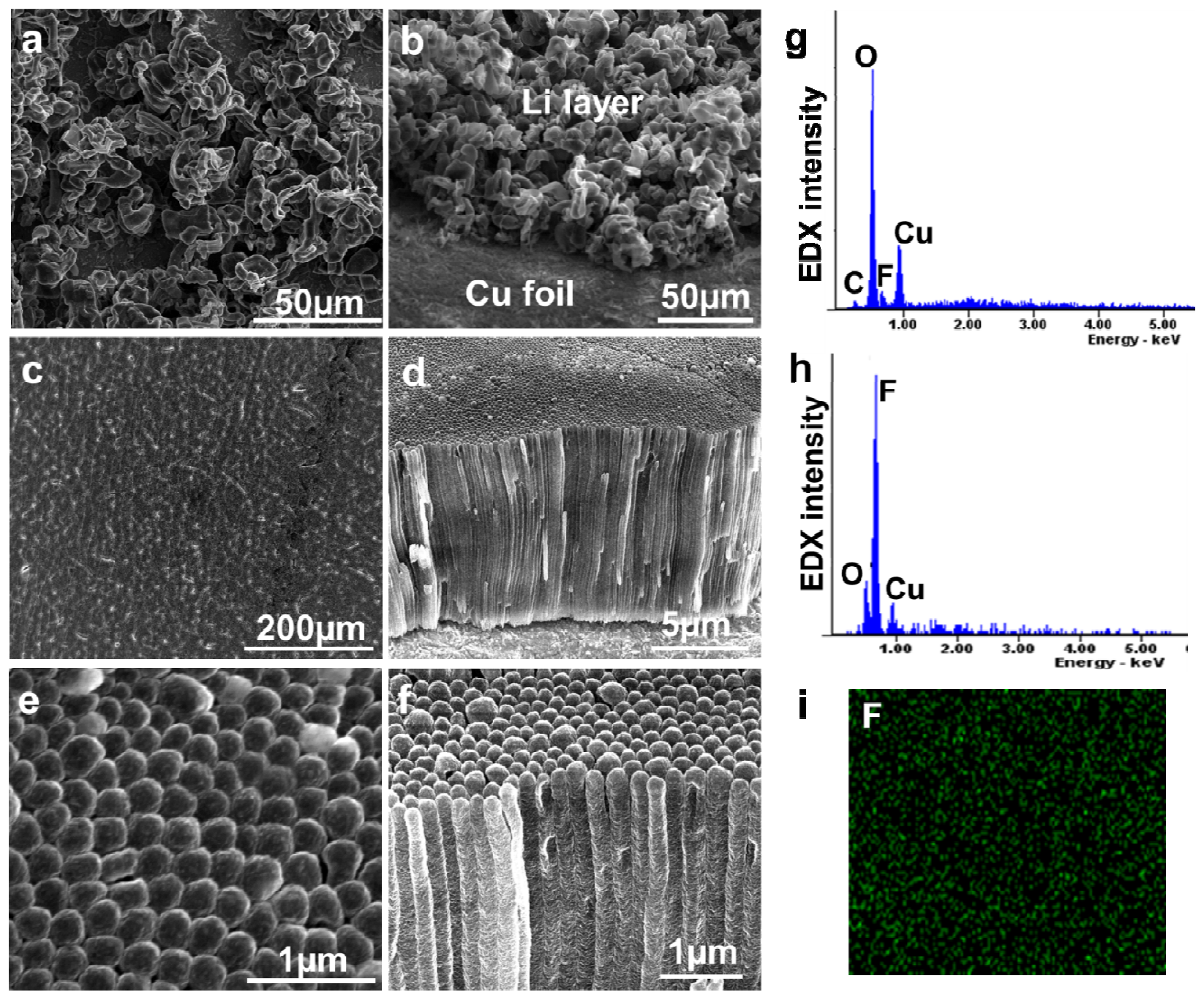

Fig. 4. SEM images of the morphologies of the electrochemically deposited Li films in the electrolyte (1.0 M LiPF $6-\mathrm{PC})(\mathrm{a}, \mathrm{b})$ without and $(\mathrm{c}, \mathrm{d}, \mathrm{e}, \mathrm{f})$ with the $50 \mathrm{ppm}_{2} \mathrm{O}$ additive at a current density of $0.1 \mathrm{~mA} \mathrm{~cm}^{-2}$ for $15 \mathrm{~h}$ : (a, c, e) surface images and (b, d, f) cross-sectional views. The images in (e) and (f) provide a higher magnification of the Li film deposited from the electrolyte with the $50 \mathrm{ppm} \mathrm{H}_{2} \mathrm{O}$ additive. (g, h) EDX spectra of the Li films obtained from the electrolytes (g) without and (h) with the $50 \mathrm{ppm}_{2} \mathrm{O}$ additive. (i) Elemental $\mathrm{F}$ mapping of the $\mathrm{Li}$ surface deposited in the electrolyte with the $50 \mathrm{ppm}_{2} \mathrm{O}$ additive.

To obtain a better understanding of the Li nanorod growth mechanism, we investigated the morphology of the deposited $\mathrm{Li}$ at different deposition times during the electrodeposition process, especially for the nucleation and growth process at the very beginning of the deposition. As shown in Fig. 5, when the voltage decreases from OCV to $0 \mathrm{~V}$, there were no distinct species deposited on the $\mathrm{Cu}$ surface (Fig. 5b) because the SEI layer formed prior to the Li deposition is too thin $(\sim 5 \mathrm{~nm}$, see Fig. S4d) to be observed by SEM. After 1 min of Li deposition, however, a large amount of nano-dots ( $<20 \mathrm{~nm}$, spherical nuclei) grow on the $\mathrm{Cu}$ substrate surface (Fig. $5 \mathrm{c}$ ), indicating Li nuclei formation. These nuclei are sporadically distributed, with large gaps between them. These nuclei gradually grow to $\sim 100 \mathrm{~nm}$ after $5 \mathrm{~min}$ (Fig. 5d) and to $\sim 200 \mathrm{~nm}$ after $10 \mathrm{~min}$ (Fig. 5e). Apparently, the nuclei growth process is accompanied by an enormous volumetric 
expansion of the Li metal, along with the continuous stretching of the SEI film covering the outside of the deposited Li. Usually, the SEI film will crack due to the stress induced when the Li is deposited underneath it, and this will force the $\mathrm{Li}$ growth along the defects into filaments and dendrites. However, as can be seen from Figs. 5d and 5e, these nuclei continue to grow larger without any notable fractures, indicating that the LiF-rich layer is strong enough to accommodate the volume change during the Li growth process. Once these nuclei grow big enough to attach to each other (Fig. 5f), there is no space for them to continue growing in a lateral direction. As a result, they must grow vertically on the $\mathrm{Cu}$ substrate, thus generating a highly compact and well aligned nanorod structure. Since all of the nucleus/nanorods were covered by the SEI layer, which prevents them from merging together, these nanorods grew separately, as seen in Fig. 4f.
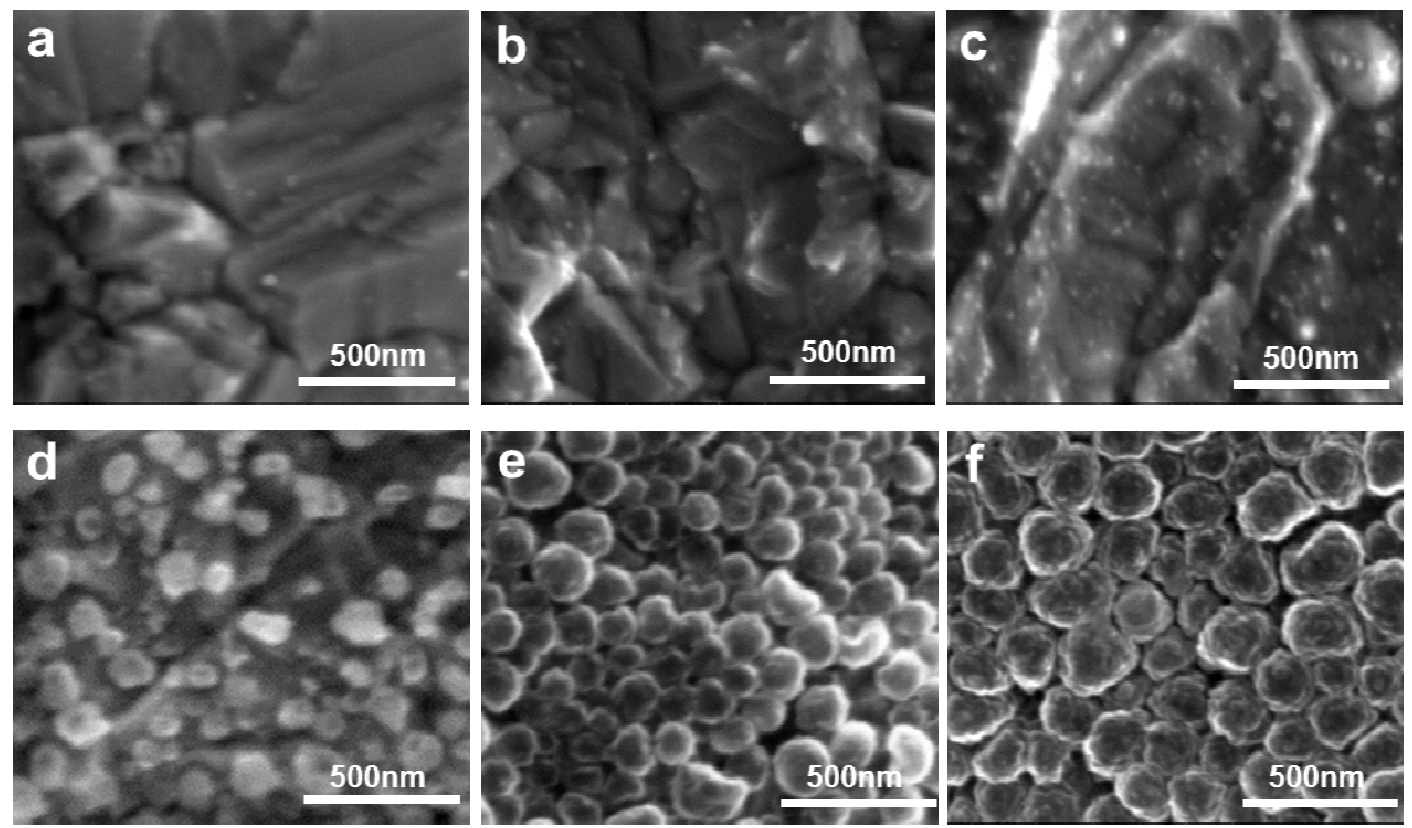

Fig. 5 Progression of the Li electrodeposition from the $1.0 \mathrm{M} \mathrm{LiPF}_{6}-\mathrm{PC}$ electrolyte with the 50 ppm $\mathrm{H}_{2} \mathrm{O}$ additive: (a) pristine $\mathrm{Cu}$ substrate, (b) $\mathrm{OCV}$ to $0 \mathrm{~V}$, (c) $1 \mathrm{~min}$, (d) $5 \mathrm{~min}$, (e) $10 \mathrm{~min}$, and (f) $1 \mathrm{~h}$ at the same current density of $0.1 \mathrm{~mA} \mathrm{~cm}^{-2}$. The scale bars in these SEM images are $500 \mathrm{~nm}$.

Here, another curious question arises: why do these closely packed spherical nuclei lead to uniform Li growth in the vertical direction? These nuclei are covered by a LiF-rich SEI layer, which is dense and uniform, likely leading to an even distribution of the electric field. In addition, it is generally known that crystal growth always involves some forms of transport of matter from solution to the nuclei, and homogeneous conditions for the transport process can only exist for spherical, cylindrical, or infinite plane surfaces. Recently, Cui and coworkers [38] reported that applying a monolayer of interconnected hollow carbon nanospheres $(800 \mathrm{~nm})$ on a $\mathrm{Cu}$ substrate enables a uniform distribution of the $\mathrm{Li}^{+}$cation flux and the current over the entire electrode surface [39]. Therefore, it is reasonable to associate the nanospheric nuclei in our experiment with the same role to favor the uniform current distribution across the electrode. Consequently, the Li nanorods grow together in the same orientation and at the same rate, which enables the formation of compact, uniform Li films. In addition, as compared with the dendritic Li electrode, the dense microstructure significantly reduces the real surface area of the Li anode, which in turn 
reduces the loss of $\mathrm{Li}$ due to the chemical and electrochemical reactions between the $\mathrm{Li}$ metal and electrolyte.

The change of the morphology of the deposited $\mathrm{Li}$ films after repeated stripping/deposition cycles was also studied. A Li film was deposited on a $\mathrm{Cu}$ substrate for $15 \mathrm{~h}$ at $0.1 \mathrm{~mA} \mathrm{~cm}^{-2}$, and then the Li was stripped for $2 \mathrm{~h}$ and re-deposited for $2 \mathrm{~h}$ at the same current density to complete one cycle. After 10 such stripping/deposition cycles, the surface and cross sectional morphologies of the Li film were examined by SEM, as shown in Figs. S5a-d. It is seen that after ten cycles the nanorod structure remained although the surface (both top and side) of the nanorods became very rough. The reason for this is believed to be due to excessive SEI formation by the chemical reactions of the freshly exposed Li surface with the electrolyte during the repeated cycling.

\section{Li deposited at different current densities}

Based upon the Li nucleation/growth patterns shown in Fig. 5, the initial nuclei density per area determines the diameter of the eventually formed nanorods. Generally, a high current density favors nuclei formation (due to an increased number of nucleation sites) and thus decreases the crystalline size of the deposits [40,41]. Here, we investigated the effect of current density on the size of electrodeposited Li nanorods. Figs. 6 and S6 show the SEM and optical images, respectively, for the Li films deposited at different current densities from 0.1 to $2.0 \mathrm{~mA}$ $\mathrm{cm}^{-2}$. At current densities from 0.1 to $1.0 \mathrm{~mA} \mathrm{~cm}$, the deposited Li films are all smooth without any protrusions on the surfaces, but the size of the nanorods decreases: $260 \mathrm{~nm}$ for $0.1 \mathrm{~mA} \mathrm{~cm}^{-2}$, $200 \mathrm{~nm}$ for $0.2 \mathrm{~mA} \mathrm{~cm}{ }^{-2}, 190 \mathrm{~nm}$ for $0.5 \mathrm{~mA} \mathrm{~cm}$, and $170 \mathrm{~nm}$ for $1.0 \mathrm{~mA} \mathrm{~cm} \mathrm{~cm}^{-2}$, which is consistent with the nucleation-controlled growth mechanism. However, when the current density is higher than $0.5 \mathrm{~mA} \mathrm{~cm}^{-2}$ (Figs. 6d-f and g-i), some cracks or holes appear on the Li surface, which could be caused by fast-deposition-induced structural defects. When the current density was increases to a much higher value of $2.0 \mathrm{~mA} \mathrm{~cm}^{-2}$ (Fig. $6 \mathrm{j}-1$ ), dendritic Li clusters grew out from the surface, indicating that the SEI layer was not thick enough to prevent dendrite growth during the Li deposition process. To improve the quality of the SEI layer, two methods were developed as shown in Fig. S7. In one approach, a small current of $0.2 \mathrm{~mA} \mathrm{~cm}^{-2}$ was used to form a uniform and thick ( $5 \mathrm{~nm}$, as shown in Fig. S4d) SEI layer and pre-deposit some Li on the $\mathrm{Cu}$ substrate for $10 \mathrm{~min}$. The current density was then increased to $2.0 \mathrm{~mA} \mathrm{~cm}^{-2}$ for another 45 min. It is anticipated that the SEI film formed with the lower current density would be thicker and more complete, thus rendering a more uniform subsequent $\mathrm{Li}$ deposition a a high current density. As seen from Fig. S7b, the Li protrusions are greatly suppressed over most of the $\mathrm{Cu}$ substrate. In another approach, $2 \%$ by weight of FEC was added to the electrolyte $\left(1.0 \mathrm{M} \mathrm{LiPF}_{6^{-}}\right.$ $\mathrm{PC}$ with the $50 \mathrm{ppm} \mathrm{H}_{2} \mathrm{O}$ additive) since $\mathrm{FEC}$ is an effective electrolyte additive for improving SEI films by its reduction to form $\mathrm{LiF}$ [42]. As anticipated, the $\mathrm{Li}$ protrusions on the surface are totally eliminated (see Fig. S7c). All of these results point to the same conclusion that a stable and uniform LiF-rich SEI layer is the most critical factor for stable and dendrite-free $\mathrm{Li}$ deposition. 

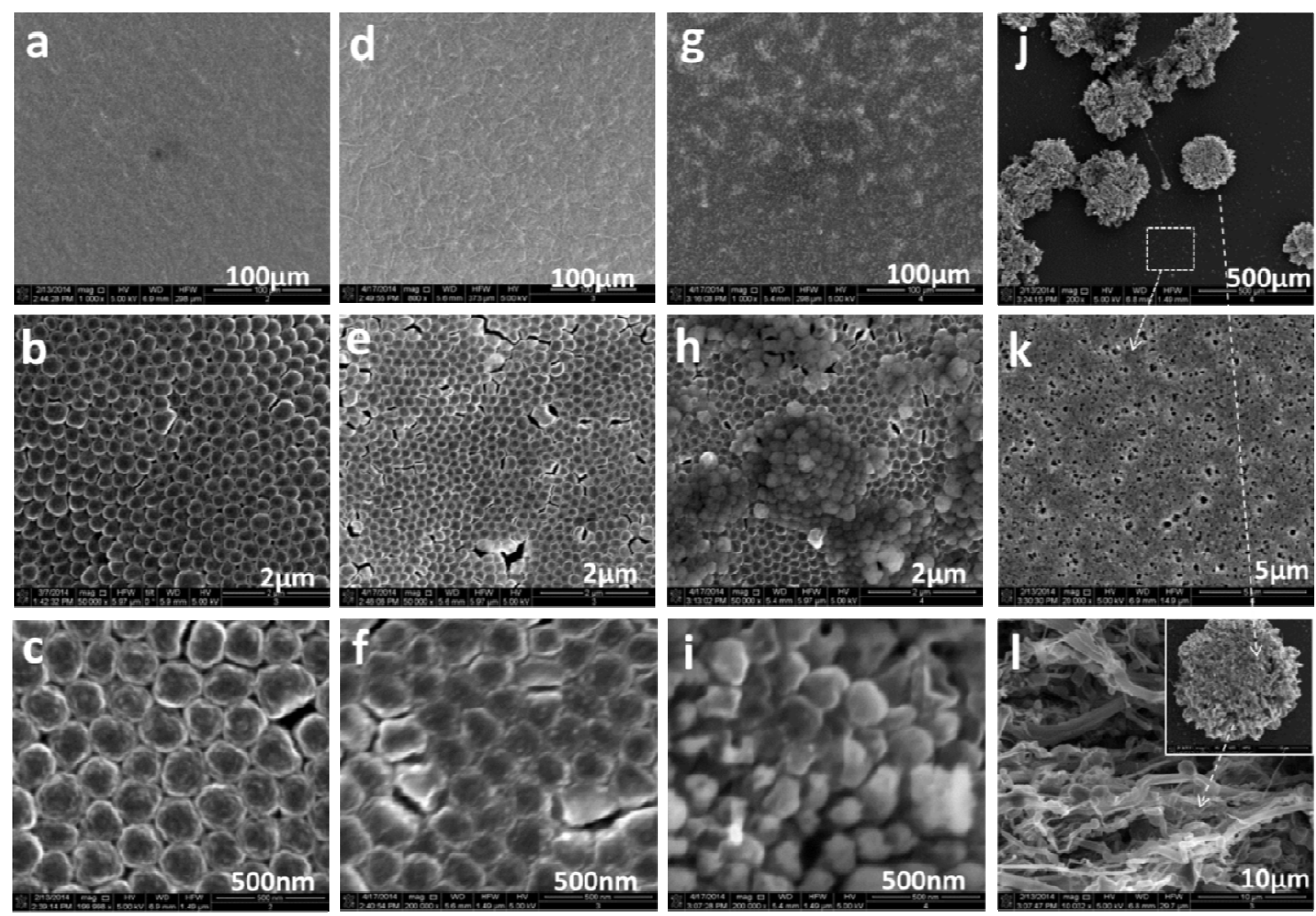

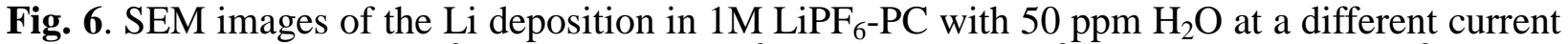
density of (a-c) $0.2 \mathrm{~mA} \mathrm{~cm}^{-2}$, (d-f) $0.5 \mathrm{~mA} \mathrm{~cm}^{-2}$, (g-i) $1.0 \mathrm{~mA} \mathrm{~cm}^{-2}$, and (j-1) $2.0 \mathrm{~mA} \mathrm{~cm}^{-2}$. The Li deposition amounts are all $1.5 \mathrm{mAh} \mathrm{cm}^{-2}$.

\section{Conclusions}

In conclusion, we have investigated the effect of $\mathrm{H}_{2} \mathrm{O}$ addition to electrolytes on Li metal electrodeposition. It is found that trace amounts $(25-50 \mathrm{ppm})$ of $\mathrm{H}_{2} \mathrm{O}$ can be an effective additive in $\mathrm{LiPF}_{6}$-based electrolytes to suppress $\mathrm{Li}$ dendrite growth during $\mathrm{Li}$ deposition. In contrast to the conventional view that $\mathrm{H}_{2} \mathrm{O}$ should be strictly excluded from non-aqueous electrolytes due to its high reactivity with the commonly used $\mathrm{LiPF}_{6}$ salt and other battery components during charge/discharge processes, here we demonstrate that a controlled trace-amount of $\mathrm{H}_{2} \mathrm{O}$ can lead to dendrite-free Li deposition. This positive effect is attributed to the trace-amount of HF formed by the hydrolytic decomposition of the $\mathrm{LiPF}_{6}$ salt. The electrochemical reduction of the asformed $\mathrm{HF}$ and other hydrolysis byproducts at voltages above $2.0 \mathrm{~V}$ in situ generates a LiF-rich SEI layer which is dense and mechanically strong. This SEI layer enables the uniform distribution of the electric field across the electrode surface and suppresses the Li dendrite growth. A nucleation-controlled Li growth mechanism is proposed to explain the self-aligned, highly-compacted nanorod structure of these $\mathrm{Li}$ films and their vibrant blue color due to structural coloration. This work provides a clear evidence of the importance of the SEI layer in terms of its composition, structure and stability during the Li deposition/stripping processes. This work further demonstrates a new, cost-effective way to address the Li metal dendrite problem by simply adding a trace-amount of $\mathrm{H}_{2} \mathrm{O}$ into a $\mathrm{LiPF}_{6}$-based electrolyte.

\section{Acknowledgments}


This work was supported by the Joint Center for Energy Storage Research (JCESR), an Energy Innovation Hub funded by the Basic Energy Sciences, Office of Science of the U.S. DOE. The SEM and EDX measurements were performed in the Environmental Molecular Sciences Laboratory (EMSL), a national scientific user facility located at PNNL and sponsored by the DOE's Office of Biological and Environmental Research. PB is grateful for support from a Linus Pauling Distinguished Postdoctoral Fellowship at PNNL.

\section{Appendix A. Supporting Information}

Supplementary data associated with this article can be found in the online version at ...

\section{References}

[1] H. Kim, G. Jeong, Y.-U. Kim, J.-H. Kim, C.-M. Park, H.-J. Sohn, Chem. Soc. Rev., 42 (2013) 9011-9034.

[2] W. Xu, J. Wang, F. Ding, X. Chen, E. Nasybulin, Y. Zhang, J.-G. Zhang, Energy Environ. Sci., 7 (2014) 513-537.

[3] A. Zhamu, G. Chen, C. Liu, D. Neff, Q. Fang, Z. Yu, W. Xiong, Y. Wang, X. Wang, B.Z. Jang, Energy Environ. Sci., 5 (2012) 5701-5707.

[4] C. Brissot, M. Rosso, J.-N. Chazalviel, S. Lascaud, J. Power Sources, 81 (1999) 925-929.

[5] D. Aurbach, Y. Cohen, J. Electrochem. Soc., 143 (1996) 3525-3532.

[6] D. Aurbach, I. Weissman, A. Zaban, O. Chusid, Electrochim. Acta, 39 (1994) 51-71.

[7] A. Kominato, E. Yasukawa, N. Sato, T. Ijuuin, H. Asahina, S. Mori, J. Power Sources, 68 (1997) 471-475.

[8] C. Monroe, J. Newman, J. Electrochem. Soc., 150 (2003) A1377-A1384.

[9] J.-i. Yamaki, S.-i. Tobishima, K. Hayashi, K. Saito, Y. Nemoto, M. Arakawa, J. Power Sources, 74 (1998) 219-227.

[10] M. Tang, P. Albertus, J. Newman, J. Electrochem. Soc., 156 (2009) A390-A399.

[11] E. Peled, J. Electrochem. Soc., 126 (1979) 2047-2051.

[12] D. Aurbach, E. Zinigrad, Y. Cohen, H. Teller, Solid State Ionics, 148 (2002) 405-416.

[13] D. Aurbach, A. Zaban, A. Schechter, Y. Ein-Eli, E. Zinigrad, B. Markovsky, J. Electrochem. Soc., 142 (1995) 2873-2882.

[14] D. Aurbach, J. Power Sources, 89 (2000) 206-218.

[15] R.L. Sacci, N.J. Dudney, K.L. More, L.R. Parent, I. Arslan, N.D. Browning, R.R. Unocic, Chem. Commun. , 50 (2014) 2104-2107.

[16] F. Ding, W. Xu, G.L. Graff, J. Zhang, M.L. Sushko, X. Chen, Y. Shao, M.H. Engelhard, Z. Nie, J. Xiao, J. Am. Chem. Soc., 135 (2013) 4450-4456.

[17] Y. Zhang, J. Qian, W. Xu, S.M. Russell, X. Chen, E. Nasybulin, P. Bhattacharya, M.H. Engelhard, D. Mei, R. Cao, F. Ding, A.V. Cresce, K. Xu, J.-G. Zhang, Nano Lett., 14 (12) (2014) 6889-6896.

[18] K. Kanamura, S. Shiraishi, Z.i. Takehara, J. Electrochem. Soc., 141 (1994) L108-L110.

[19] K. Kanamura, S. Shiraishi, Z.i. Takehara, J. Electrochem. Soc., 143 (1996) 2187-2197.

[20] N. Togasaki, T. Momma, T. Osaka, Journal of Power Sources, 261 (2014) 23-27.

[21] Y. Lu, Z. Tu, L.A. Archer, Nature Mater., 13 (2014) 961-969.

[22] Z. Chen, Y. Ren, A.N. Jansen, C.-k. Lin, W. Weng, K. Amine, Nature Commun., 4 (2013) 
1513.

[23] A.V. Plakhotnyk, L. Ernst, R. Schmutzler, J. Fluorine Chem., 126 (2005) 27-31.

[24] D. Aurbach, I. Weissman, A. Zaban, P. Dan, Electrochim. Acta, 45 (1999) 1135-1140.

[25] L. Terborg, S. Nowak, S. Passerini, M. Winter, U. Karst, P.R. Haddad, P.N. Nesterenko, Analytica chimica acta, 714 (2012) 121-126.

[26] J. Burns, N. Sinha, G. Jain, H. Ye, C.M. VanElzen, E. Scott, A. Xiao, W. Lamanna, J. Dahn, J. Electrochem. Soc., 160 (2013) A2281-A2287.

[27] S. Meini, M. Piana, N. Tsiouvaras, A. Garsuch, H.A. Gasteiger, Electrochem. Solid-State Lett., 15 (2012) A45-A48.

[28] Z.-Z. Gu, H. Uetsuka, K. Takahashi, R. Nakajima, H. Onishi, A. Fujishima, O. Sato, Angew. Chem., Int. Ed., 42 (2003) 894-897.

[29] L.J. Krause, W. Lamanna, J. Summerfield, E. Mark, G. KOrba, R. Loch, AtanasoskiRadoslav, Journal of Power Sources, 68 (1997) 320-325.

[30] R. Dedryvère, L. Gireaud, S. Grugeon, S. Laruelle, J.M. Tarascon, D. Gonbeau, J. Phys. Chem. B, 109 (2005) 15868-15875.

[31] S.-P. Kim, A.C.T.v. Duin, V.B. Shenoy, J. Power Sources, 196 (2011) 8590-8597.

[32] J. Zheng, H. Zheng, R. Wang, L. Ben, W. Lu, L. Chen, L. Chen, H. Li, Phys. Chem. Chem. Phys., 16 (2014) 13229-13238.

[33] S.-L. Shang, L.G. Hector Jr, S. Shi, Y. Qi, Y. Wang, Z.-K. Liu, Acta Materialia, 60 (2012) 5204-5216.

[34] M.C. Billone, Y.Y. Liu, R.B. Poeppel, J.L. Routbort, K.C. Goretta, D.S. Kupperman, J. Nucl. Mater., 141-143 (1986) 282-288.

[35] L.S. Combes, S.S. Ballard, K.A. McCarthy, J. Opt. Soc. Am. Journal of the Optical Society of America, 41 (1951) 215-221.

[36] D. Gunceler, K. Letchworth-Weaver, R. Sundararaman, K.A. Schwarz, T. Arias, Modelling Simul. Mater. Sci. Eng., 21 (2013) 074005.

[37] M.S. Park, S.B. Ma, D.J. Lee, D. Im, S.-G. Doo, O. Yamamoto, Sci. Rep., 4 (2014) 3815.

[38] G. Zheng, S.W. Lee, Z. Liang, H.-W. Lee, K. Yan, H. Yao, H. Wang, W. Li, S. Chu, Y. Cui, Nature Nano., 9 (2014) 618-623.

[39] A.J. Bard, L.R. Faulkner, Electrochemical methods: fundamentals and applications, 2nd, 2001.

[40] A.M. Rashidi, A. Amadeh, Surf. Coat. Technol., 202 (2008) 3772-3776.

[41] J. F. Qian, W. A. Henderson, W. Xu, P. Bhattacharya, M. Engelhard, O. Borodin, J-G. Zhang, Nat. Commun. 6:6362 doi: 10.1038/ncomms7362 (2015).

[42] X. Chen, X. Li, D. Mei, J. Feng, M.Y. Hu, J. Hu, M. Engelhard, J. Zheng, W. Xu, J. Xiao, J. Liu, J.-G. Zhang, ChemSusChem, 7 (2013) 549-554. 


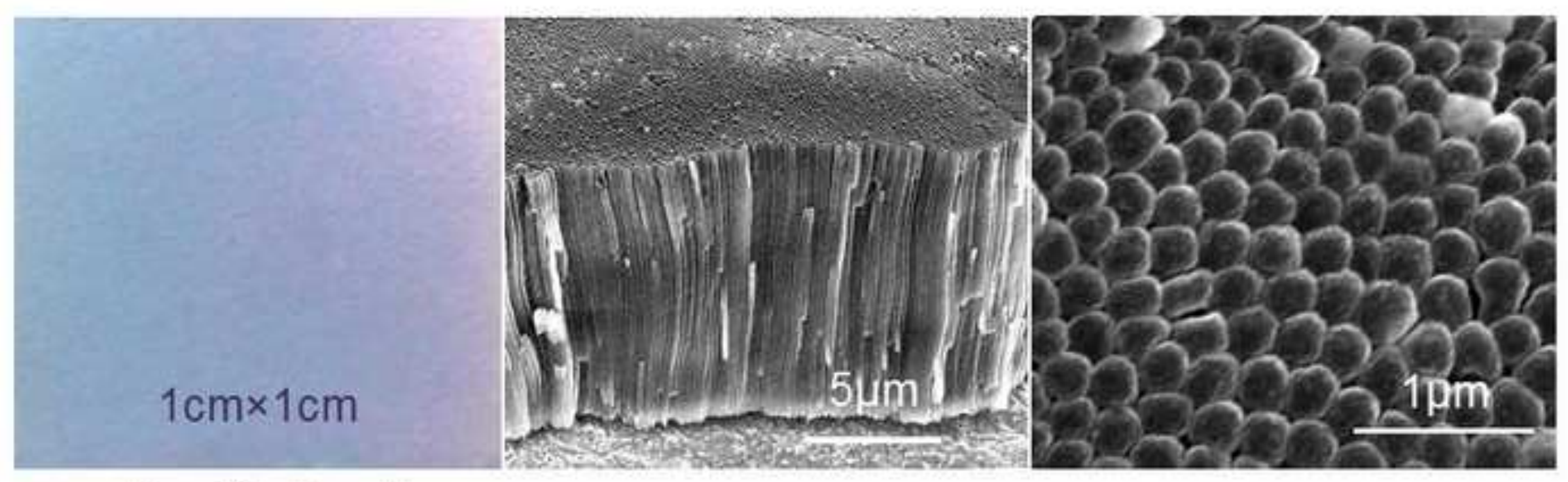

\section{Dendrite-free Li deposition using water as additive (1)}

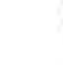

Cross-sectional and top views of Li nanorod structure 